Souza, D. A., Marchesan, W. G. \& Greene, L. J. (1998) Epidemiological data and mortality rate of patients hospitalized with burns in Brazil. Burns, 24, 433-438.

Souza, E. R. (199|) Violência velada e revelada: estudo epidemiológico da mortalidade por causas externas em Duque de Caxias - R]. [Concealed and revealed violence: epidemiological study of external causes of mortality in Duque de Caxias - Riojaneiro.] Masters dissertation, Escola Nacional de Saúde Pública, Rio de Janeiro.

Souza, E. R., Minayo, M. C. S. \& Malaquias, J. (2002) Suicídio de jovens nas principais capitais do Brasil, Rio de Janeiro. [Youth suicide in major Brazilian capitals, Rio de Janeiro.] Cadernos de Saúde Pública, 18, 673-683.
Teixeira, A. M. F. \& Villar Luis, M. A. ( 1997) Distúrbios psiquiátricos, tentativas de suicídio, lesões e envenenamento em adolescentes atendidos em uma unidade de emergência, Ribeirão Preto, São Paulo, 1988-1993. [Mental disorder, suicide attempt, lesions and assistance in an emergency unit for youth poisoning, Riberão Preto, São Paulo, 1988-1993.] Cadernos de Saúde Pública, I3 517-525.

World Health Organization (1992) International Classification of Diseases and Related Health Problems (I0th revision) (ICD-I0). Geneva: WHO.

World Health Organization (1999) Figures and Facts About Suicide (doc. WHO/MNH/MBD/99. I). Geneva: WHO.

\title{
Perspectives on suicide in Africa
}

\section{N. K. Ndosi MD PhD}

Associate Professor, Department of Psychiatry, MUCHS PO Box 65051, Dar es Salaam, Tanzania, email nkndosi@hotmail.com

\begin{abstract}
uicide is a serious worldwide health problem, particularly among youths. It is defined as the intentional act of killing oneself. Analytically, the suicidal act entails: the wish to kill, the wish to be killed and the wish to die. People who die by suicide know what they are doing and are aware of the consequences of their actions. A completed suicidal act is a complex phenomenon associated with psychological, biological and social factors. It follows severe exhaustion under a continuing assault of stressors when the suicidal individual is no longer able to cope with and to restore homeostasis. In order to categorise a case as a suicide, legal authorities demand unequivocal evidence of intent.
\end{abstract}

\section{Common determinants of suicide}

In many traditional African cultures people fear death by suicide and it is one of the strongest taboos. In East Africa suicide is a terrible event for family and close friends (Swift, 1977, p. I18). Rates of suicides were considered to be low in Africa as a result of both a paucity of depressive conditions and frequent communal clashes that diverted aggression away from the self and towards others (Elliott, 200 I). This view is no longer tenable, however. Depression in Africans is not readily recognised, as it tends to present with somatisation, rather than feelings of guilt and self-reproach, unlike in Western cultures (Morgan, 1979).

Although there is rather little information on the causes of suicide in sub-Saharan Africa, there are indicators that the rates are rising, particularly among young people, and that the majority of cases result from overwhelming social factors (Lister \& Wilson, 1990; Nwosu \& Odesamni, 200 I; Ndosi et al, 2004).

Rapid urbanisation in Africa is undermining the prevailing networks for social support and causing the social alienation of individuals. The ensuing diverse psychosocial pathologies increasingly predispose people to suicide (Ndosi, 2005). Young people experience more stress in relation to their as yet unmet expectations and demands from their governments. When emotionally overwhelmed, in the absence of people to confide in, they tend to develop suicidal thoughts.

Continuing poverty among Africans threatens the very fabric of existence. Some 340 million Africans live on less than US\$I per day (Heggenhougen \& Lugalla, 2005, pp. 29I-300). Extreme poverty destabilises lives, crushes self-esteem and creates despair, and this can lead to self-harm. Poverty marginalises, stigmatises and erodes human decency and leads to dependence and powerlessness. Unemployment and underemployment (as petty traders or lowly paid workers) subject young adults to hardships which enhance ruminations of self-destruction.

The gender identity of the majority of sub-Saharan women is deeply embedded in a cultural context of male dominance. Many women are thus pushed into defeat and helplessness, which makes them vulnerable. Conjugal relationships are fraught with jealousies, grief, feelings of abandonment and fear of contracting sexually transmitted diseases (Kabeer, 1993). Culturally, men have the right to discipline their wives, and wifebeating is widespread. Anger, shame and despair attain overwhelming levels, and suicide can be an expression of intolerable distress.

Despite the paucity of data, clinical observations indicate that a considerable proportion of young females who have become pregnant unexpectedly attempt and complete suicide when they are abandoned by their male partners (Ndosi \& Waziri, 1997; Ndosi et al, 2004).

In clinical practice, about $90 \%$ of people who die by suicide suffer from an underlying psychiatric disorder (Ndosi et al, 2004). The risk of patients with a mental illness killing themselves is 3-12 times greater than that of people without psychiatric illness. In particular, the lack of dependable social support for those with schizophrenia can make them feel lonely and unwanted. They continue to suffer from the stigma attached to mental illness in their communities,
Depression in

Africans is not readily recognised, as it tends to present with somatisation, rather than feelings of guilt and self-reproach, unlike in Western cultures. 
and nearly a tenth of these patients complete suicide (Ndosi et al, 2004). The risk is higher among patients with poor adherence to medication, especially during the first 4 weeks after hospital discharge.

Young people with a personality disorder and from broken homes, who are often homeless or forced to reside in squats, tend to react impulsively with suicidal behaviour when overburdened by stress in their environments. Some of these youngsters misuse drugs and lead chaotic lifestyles. They often accumulate financial debts as a result of their addiction, which triggers severe interpersonal conflicts and emotional outbursts that culminate in selfharm. Heroin misuse among young males in urban sub-Saharan settings is on the increase. The risk of suicide among heroin misusers has been estimated to be 20 times that in the general population (Ndosi et al, 2004).

Clinical observation indicates that alcohol dependence in sub-Saharan countries has lately increased considerably, and alcoholism has been noted to be the second most common psychiatric disorder among individuals who complete suicide. In a third of suicides in Dar es Salaam, alcohol was found to be an associated factor (Ndosi et al, 2004).

Patients with HIV infection have been found to be 35-40 times more likely to kill themselves than HIV-negative persons (Rajs \& Fugelstad, 1992). Studies conducted in four African cities have shown an increased rate of suicidal ideation, suicidal attempts and completed suicide in individuals with HIV and AIDS (Buve et al, 200I). Among suicides in Dar es Salaam, the rate of HIV seropositivity was found to be at least twice that in the normal population. The suicide risk among poor HIV-positive persons tends to be higher if the HIV infection is advanced and accompanied by disabling illness.

The prevalence of epilepsy in poor African countries is notably high. People with the condition have a fivefold higher risk of killing themselves. This risk may be very much higher still in those with temporal lobe epilepsy.

\section{Usual methods of suicide}

Methods selected to complete suicide vary with age and availability, and are influenced by cultural values and social policy. Males outnumber females in violent methods of self-destruction. Culturally, African men are expected to summon stiffer resolve in difficult life situations. They show greater intent in their suicidal acts, which typically involve hanging, slashing or stabbing and gunshots, whereas females predominantly opt for poisoning. Uneducated and unemployed people in rural areas use hanging more frequently than the better educated, who prefer firearms more often. Insecticides, rodent poisons, organophosphates, DDT, kerosene and cheap chemicals are frequently used in cases of fatal self-poisoning in rural farming populations.
It is not surprising that rates of deliberate overdose in recent years appear to be increasing, as a result of the ready availability (over the counter) of therapeutic drugs (Mbatiya, 1997). The drugs commonly used include chloroquine (especially in malaria-prone regions), antibiotics, aspirin, paracetemol, psychotropic drugs, dilute sulphuric acid, antiseptic solutions and deworming medicaments.

\section{Prevention}

Strategies to prevent suicide need to employ traditional approaches that focus on community-based and clinical interventions. They should include restricting access to lethal means, providing services to highrisk groups and making medical services rapidly available. A suicidal patient needs emergency evaluation and help. Underlying psychiatric disorders have to be treated aggressively. Severe mental symptoms of depression, psychosis, aggression, impulsive acts and suicidal behaviour, when the capacity to cope is overstrained without reliable social support, call for hospital admission. Prevention of suicide includes precautions such as removing lethal drugs or firearms and dangerous objects from patients. Attempted suicide is one of the strongest indicators of suicide. The circumstances under which a suicide attempt was made and the choice of means can give some clue as to the seriousness of the risk.

\section{References}

Buve, A., Lagarde, E., Carael, M., et al (200I) Study Group on Heterogeneity of HIV Epidemics in African Cities. Interpreting sexual behaviour data: validity issues in the multicentre study on factors determining the differential spread of HIV in four African cities. AIDS, I5 (suppl. 4), | |7-126.

Elliott, M. (200I) Gender differences in causes of depression. Women's Health, 33, 163-177.

Heggenhougen, K. H. \& Lugalla, J. P. (eds) (2005) Social Change and Health in Tanzania. Dar es Salaam: Dar es Salaam University Press.

Kabeer, N. (1993) Reversed Realities: Gender Hierarchies in Development Thought. London: Verso.

Lister, D. \& Wilson, C. (1990) Teenage suicide in Zimbabwe. Adolescence, 25, 807-809.

Mbatiya, Z. A. ( 1997) The Availability and Use of Anti-malarial Drugs in Households in Kibaha District, Tanzania, 1996. Dissertation in partial fulfilment of the requirements for the Degree of Master of Science in Tropical Diseases Control at the University of Dar es Salaam.

Morgan, H. G. (1979) Death Wishes? The Understanding and Management of Deliberate Self-harm. Chichester: Wiley.

Ndosi, N. K. (2005) The challenges of psychiatry amidst economic deprivations and social change in Dar es Salaam City, Tanzania. In Social Change and Health in Tanzania (eds K. H. Heggenhougen \& J. P. Lugalla), pp. 196-208. Dar es Salaam: Dar es Salaam University Press.

Ndosi, N. K. \& Waziri, M. C. (1997) The nature of attempted suicide in Dar es Salaam. Social Science and Medicine, 44, 55-6I.

Ndosi, N. K., Mbonde, M. P. \& Lyamuya, E. L. (2004) Profile of suicide in Dar es Salaam. East African Medical Journal, 8I, 207-211.

Nwosu, S. O. \& Odesamni, W. O. (200I) Patterns of suicides in lleIfe, Nigeria. West African Journal of Medicine, 20, 259-262.

Rajs, J. \& Fugelstad, A. (1992) Suicide related to human immunodeficiency virus infection in Stockholm. Acta Psychiatrica Scandinavica, 85, 234-237.

Swift, C. R. (1977) Mental Health (Rural Health Series 6). Nairobi: African Medical and Research Foundation. 